\title{
Design Issues of an IPM Motor for EPS
}

\section{Caifei Wang ${ }^{1,2}$, Jianxin Shen ${ }^{1}$, Patrick Chi-Kwong Luk ${ }^{2}$, Weizhong $\mathrm{Fei}^{2}$, and Mengjia Jin ${ }^{1}$}

\author{
(1. College of Electrical Engineering, Zhejiang University, Hangzhou, 310027, China \\ 2. Department of Engineering Systems and Management, Cranfield University, Shrivenham, SN6 8LA, UK) \\ *E-mail: j_x_shen@zju.edu.cn \\ Topic: EV3-a; Presentation perferrence: Poster.
}

\begin{abstract}
In electric power steering (EPS), permanent magnet (PM) brushless ac (BLAC) motors offer distinct advantages over other electric motor types in terms torque smoothness, reliability and efficiency. The design procedure of an interior permanent magnet (IPM) motor used in EPS is presented in this paper. The requirements of the steering system are first introduced, and the machine's specifications are then derived. Critical issues which have considerable impacts on the machine's performance, such as operation mode, rotor structure and slot/pole combination, are analyzed. Subsequently, a 12-slot/10-pole sinusoidally excited IPM machine with concentrated windings is proposed and optimized based on finite element analysis (FEA) modelling. The losses and efficiency are then computed. Performance predictions from the FEA results confirm all the requirements are met or exceeded. A prototype motor has been built for validation.
\end{abstract}

Keywords: Electric power steering, interior permanent magnet, motor design, finite element analysis.

\section{Introduction}

Global warming is becoming a very important global issue. It was even one of the three main topics in the recent 2009 G8 Summit. Carbon dioxide $\left(\mathrm{CO}_{2}\right)$ emission is the main contributor of green house gas which leads to global warming. Transportation accounts for more than $20 \%$ of man-made $\mathrm{CO}_{2}$ [1]. It is therefore highly desirable to reduce green house gas emission by improving vehicles' fuel efficiency. On the other hand, the number of electric machines installed in modern vehicles has been increasing at a rapid pace. The more luxury the vehicle, the more electric machines will be equipped. Well optimised electric machines with high efficiency will therefore play a pivotal role in improving the vehicles' overall efficiency, and thus in reducing the $\mathrm{CO}_{2}$ emission to mitigate global warming.

An apparent trend that electrical power steering (EPS) is becoming an alternative to the hydraulic power steering (HPS) can be seen in recent developments in automotive industry. In the HPS system, a pump driven by the engine is constantly running to keep the hydraulic pressure, no matter assistance is required or not. While in the EPS system, the electric motor is driven only when the steering wheel is turned. EPS thus offers much better fuel economy, which can account for 3\% improvements in fuel efficiency [2].

Electric machines, the key actuators in the EPS system, are crucial in influencing the vehicle's steering performance. A brushed DC motor was equipped in the world's first EPS system in 1993 by Honda, on Acura NSX [3]. Presence of brushes limits its performance especially at higher speeds, and the sparks may cause safety and electromagnetic interference (EMI) problem. A much more competitive solution based on permanent magnet (PM) brushless machines has drawn considerable interests from both industrial and academic research communities. The high torque/volume ratio, high dynamics, high speed due to fieldweakening capability and absence of brushes, simple machine structure and high efficiency are some of the advantages of PM machines. For the disadvantages, the magnets will subject to the risk of irreversible demagnetization in overloading or high temperature conditions. Various PM machine topologies have been developed for EPS applications. Research have been focusing on some particular aspects, such as cogging torque reduction and torque ripple minimization [4]-[8], saturation effect [9]-[11], losses [12] [13], and fault tolerance [3] [14] [15]. Whereas most studies principally focus on the electromagnetic design level on the size and shape of the magnets of the machine, it appears that few studies emphasize on machine topology selection level prior to detailed machine electromagnetic design. For a complete EPS system design procedure, it is strongly felt that essential issues for machine 
characteristics, including machine topology, operation mode, and slot/pole combination, should be firstly decided.

This paper concerns the design of a PM machine for EPS applications. The requirements of the EPS application are introduced and the specifications of the desired machine are then derived. Before detailed design, some critical issues which essentially affect the final performance, viz., operation mode of either brushless alternating current (BLAC) or brushless direct current (BLDC), rotor structure of either surface-mounted permanent magnet (SPM) or IPM, as well as slot/pole combination, are analyzed in details. Subsequently, a 12-slot/10-pole sinusoidally excited IPM machine with concentrated windings is optimally designed and verified with finite element analysis (FEA). A prototype has been built for validation.

\section{Application requirements and design specifications}

\section{A. Application overall requirements}

EPS is an important subsystem on vehicles, which works extremely frequently during driving. In such a safety critical application, high reliability must be fully considered during the whole design process. Besides, in terms of limited available space and the demanding working environments, the desired electric machine is to have following features: compact size, low weight, low cost, variable speed over wide torque-speed areas, low acoustic and electromagnetic noise, high efficiency, as well as smooth torque output for the precision steering and driving comfort.

\section{B. Design specifications}

For small and middle sized vehicles, the electric machine is mounted on the pinion steering gear or on the steering column. Assistant torque is applied to the steering column via a worm-gear. Therefore, the electric machine can run at relatively higher speed. About $6 \sim 8 \mathrm{kN}$ column force is required in this EPS system, which corresponds to 7 $\mathrm{Nm}$ torque demand for electric machine [16] [17]. The specifications for the desired electric machine under study, which is to be used in a column-type EPS, are summarized in Table I. The required torque-speed curve is shown in Figure 1.
Table I: Specifications of desired electric machine for EPS application.

\begin{tabular}{|c|c|}
\hline DC-bus voltage & $42 \mathrm{~V}$ \\
\hline Stall torque & $7 \mathrm{Nm}$ \\
\hline Base speed & $600 \mathrm{rpm}$ \\
\hline Maximum speed & $2000 \mathrm{rpm}$ \\
\hline Torque ripple & $<3 \%$ \\
\hline
\end{tabular}

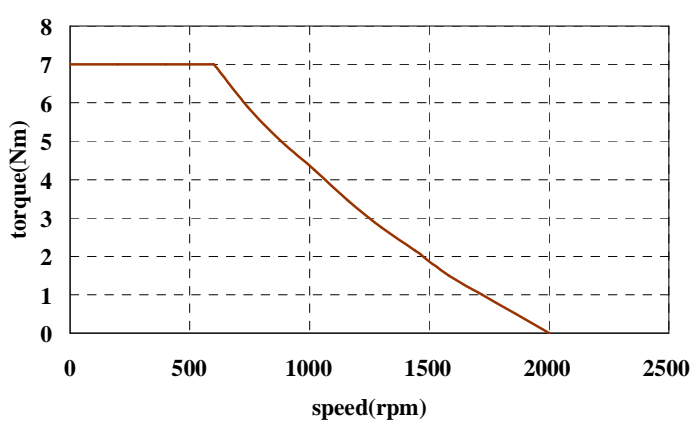

Figure 1: Torque-speed curve of desired electric machine for EPS application.

\section{Discussion on critical design issues}

Great attention should be paid to certain critical issues which primarily impact the machine's output characteristics. These critical issues mainly include operation mode, rotor structure and slot/pole combination.

\section{A. Operation mode}

PM Brushless machines could be driven in both BLDC and BLAC modes. The definitions of BLDC and BLAC mode are related to the waveforms of the back electromotive force (back-EMF) and the driving current [18], viz.,

- BLDC: Trapezoidal back-EMF with rectangular current;

- BLAC: Sinusoidal back-EMF with sinusoidal current.

The typical torque-speed performances [19] of brushless motor driven with BLDC and BLAC modes are shown in Figure 2.

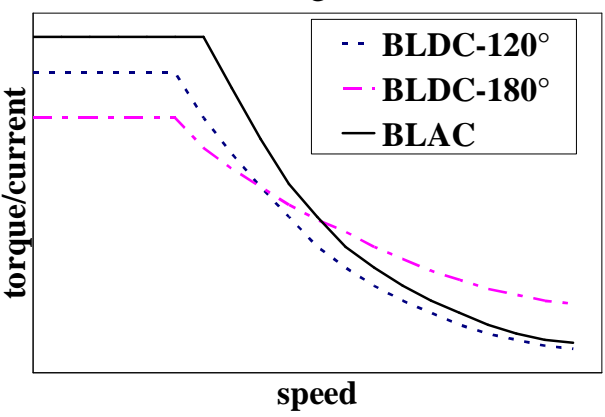

Figure2: Typical torque-speed curves with different operation modes.

For EPS applications, the electric machine usually runs at low or medium speeds. Then 
the BLAC mode is preferred as it can achieve a higher torque output at lower speed. Additionally, the BLAC mode usually results in much smaller torque ripple than the BLDC mode [7], which is highly desirable in EPS applications. Hence, the BLAC mode should be employed, whilst the sinusoidal back-EMF has to be guaranteed.

\section{B. Rotor structure}

PM machines provide many possibilities to place magnets on rotors, which can be broadly divided into the SPM or IPM categories according to the fixtures of the PM onto the rotor core. The main SPM types are shown in Figure 3 (a), (b); whereas the main IPM types are shown in Figure 3 (c), (d).

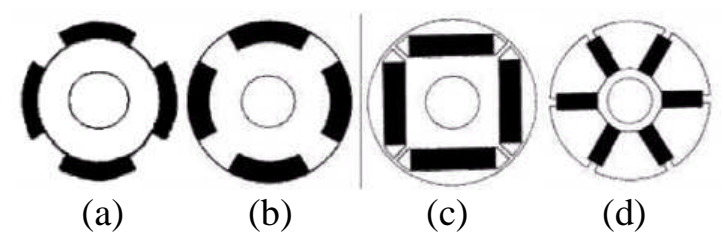

Figure3: Different PM rotor structures, (a) and (b): SPM; (c) and (d): IPM.

Based on $d q$-coordinates, the electromagnetic torque can be calculated as,

$T_{e}=\frac{3}{2} p\left[\lambda_{m} \cdot i_{q}+\left(L_{d}-L_{q}\right) i_{d} \cdot i_{q}\right]$

where $p$ is the number of pole pairs, $\lambda_{m}$ is the PM-excited flux linkage, $i_{d}, i_{q}, L_{d}$ and $L_{q}$ are $d$, $q$-axes currents and inductances, respectively.

For SPMs of type shown in Figure 3(a), where $L_{d}=L_{q}$, the last item in equation (1) is zero. On the contrary, $L_{d}<L_{q}$ for SPMs of type shown in Figure 3(b) and also for the IPMs. Thus, an extra torque boost can be obtained by applying appropriate $i_{d}$ and $i_{q}$, which is so called reluctance torque [20].

Though SPMs can offer slightly better dynamics due to smaller inductances as a result of low (air-like) permanence of the magnets, IPMs can easily achieve the ideal sinusoidal back-EMF which is tremendously required in BLAC mode. Furthermore, IPMs own many other advantages over SPMs, as will be discussed in the next section.

\section{Slot/pole combination}

The concentrated windings allow many combinations of slots and poles to PM machines. Different slot/pole combinations have extensive influence on machine characteristics, such as back-EMF, cogging torque, losses and efficiency [2] [18].
Common slot/pole number combinations for 3phase, non-overlapping winding electric machines are,

$\frac{N_{s}}{N_{p}}=k\left(\frac{3}{2}\right), k=1,2,3 \cdots \cdots$

where $N_{s}$ and $N_{p}$ are numbers of slots and poles, respectively. These machines, $3 \mathrm{~s} / 2 \mathrm{p}$, $6 s / 4 p, 9 s / 6 p$ and $12 s / 9 p$, inevitably suffer low usage of windings with a winding factor of 0.866 .

In order to maximize the winding flux-linkage and power density, coil-pitch should be equal to pole-pitch, which means slot number is equal to pole number. These combinations present maximum flux-linkage and power density, but also large cogging torque, and are therefore only suitable for single phase motors. Thus, the realistic combination of slots and poles should aim at 'coil-pitch $\approx$ pole-pitch' rather than 'coil-pitch = pole-pitch'. Therefore, $N_{s}$ and $N_{p}$ differing by 1 and 2 are the two closest cases.

- Case 1: $N_{s}$ and $N_{p}$ differed by 1 , viz.,

$$
\left|N_{s}-N_{p}\right|=1
$$

Electric machines with these slot/pole combinations such as $3 \mathrm{~s} / 2 \mathrm{p}, 3 \mathrm{~s} / 4 \mathrm{p}, 9 \mathrm{~s} / 8 \mathrm{p}$, $9 \mathrm{~s} / 10 \mathrm{p}$, show a number of merits, including high flux linkage per coil, high torque density and negligible cogging torque. However, there will be a potential weakness in terms of unbalanced magnetic force, which results in vibration and acoustic noise, as well as decreased lifecycle.

- Case 2: $N_{s}$ and $N_{p}$ differed by 2, viz.,

$$
\left|N_{s}-N_{p}\right|=2
$$

Machines with these slot/pole combinations, for instance, $6 s / 4 p, 6 s / 8 p, 12 s / 10 p, 12 s / 14 p$, indicate similarly remarkable attributes, such as high torque density and small cogging torque. Moreover, there is no risk of unbalanced magnetic force.

The analysis shows that Case 2 to be the better option, and the 12s/10p combination has therefore been chosen for this application. The potential merits are confirmed by the comparison of back-EMF waveforms with different slot/pole combinations, as shown in Figure 4 . It is clearly shown that the $12 \mathrm{~s} / 10 \mathrm{p}$ offers more sinusoidal back-EMF than others. 


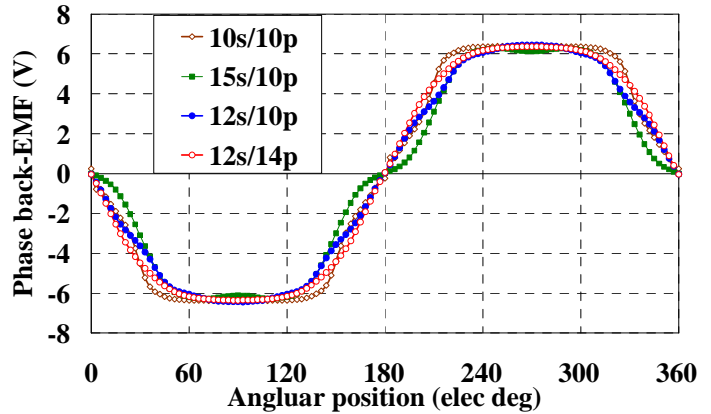

Figure4: Back-EMF waveforms with different slot/pole combinations.

\section{Proposed machine}

The foregoing discussion has led to an initial model selection of a $12 \mathrm{~s} / 10 \mathrm{p}$ IPM machine, which is to be driven in BLAC mode. The design of the PM's shape and other machine parameters can now be effectively completed. The key parameters are listed in Table II, including the winding configuration and rotor shape modification. The proposed machine optimized by FEA is shown in Figure 5 .

Table II: Machine parameters.

\begin{tabular}{|c|c|c|c|}
\hline Symbol & Machine Parameter & Value & Unit \\
\hline$N_{s}$ & Number of slots & 12 & \\
\hline$N_{p}$ & Number of poles & 10 & \\
\hline$m$ & Number of Phases & 3 & \\
\hline \multirow[t]{4}{*}{$N_{\text {coil }}$} & $\begin{array}{c}\text { Number of turns } \\
\text { per coil }\end{array}$ & 30 & \\
\hline & PM material & NdFeB35 & \\
\hline & $\begin{array}{c}\text { Magnetization } \\
\text { orientation }\end{array}$ & Parallel & \\
\hline & $\begin{array}{c}\text { Stator and rotor } \\
\text { lamination material }\end{array}$ & $35 \mathrm{~W} 470$ & \\
\hline$K_{p}$ & Slot fill factor & $54 \%$ & \\
\hline$R_{s o}$ & Stator outer radius & 75.0 & $\mathrm{~mm}$ \\
\hline$R_{s i}$ & Stator inner radius & 41.0 & $\mathrm{~mm}$ \\
\hline$R_{o}$ & Rotor outer radius & 40.0 & $\mathrm{~mm}$ \\
\hline$g$ & Air gap & $0.5 \sim 0.95$ & $\mathrm{~mm}$ \\
\hline$w_{p m}$ & PM width & 10.0 & $\mathrm{~mm}$ \\
\hline$t_{p m}$ & PM thickness & 2.0 & $\mathrm{~mm}$ \\
\hline$w_{s t}$ & Stator tooth width & 5.0 & $\mathrm{~mm}$ \\
\hline$l_{a}$ & Active axial length & 70 & $\mathrm{~mm}$ \\
\hline$J_{\text {peak }}$ & $\begin{array}{c}\text { Rated peak current } \\
\text { density }\end{array}$ & $1.7 \mathrm{e} 7$ & $\mathrm{~A} / \mathrm{m}^{2}$ \\
\hline$U_{d c}$ & DC-link voltage & 42 & $\mathrm{~V}$ \\
\hline$P_{e m}$ & Rated power output & 435 & W \\
\hline$I_{\text {peak }}$ & $\begin{array}{l}\text { Rated peak phase } \\
\text { current }\end{array}$ & 14 & A \\
\hline$R_{p h}$ & $\begin{array}{c}\text { Phase resistance } \\
\left(100{ }^{\circ} \mathrm{C}\right)\end{array}$ & 0.27 & $\Omega$ \\
\hline
\end{tabular}

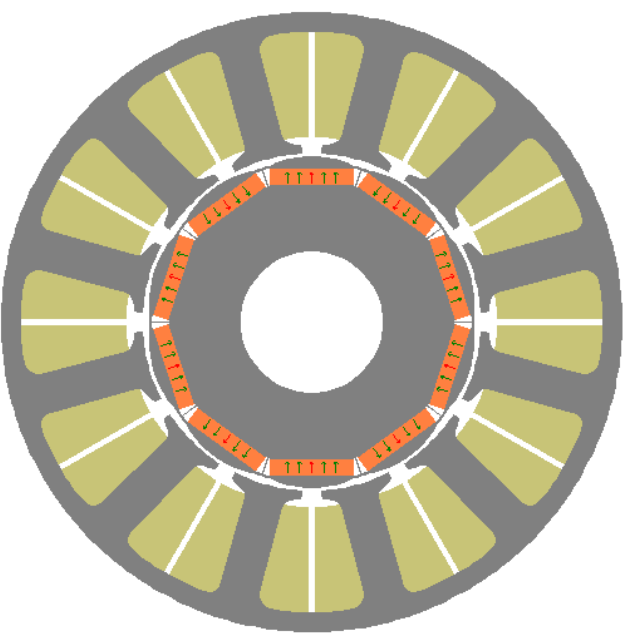

Figure 5: Cross section of the proposed machine.

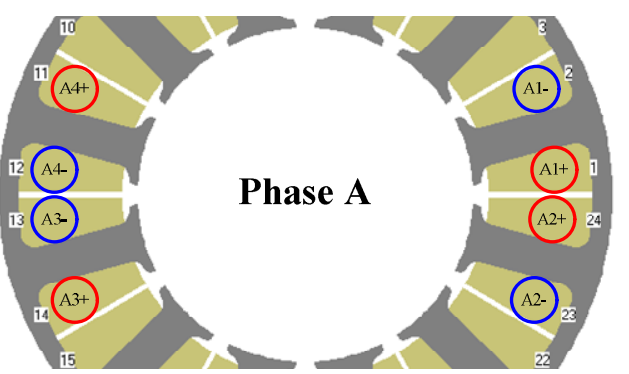

Figure.6: Winding configuration of the proposed machine.

\section{A. Winding configuration}

Non-overlapping concentrated windings are adopted, which exhibit outstanding features of high winding factor (0.933) and short end winding. Only phase A is illustrated in Figure 6.

\section{B. Rotor shape modification}

As mentioned previously, sinusoidal backEMF is required for the BLAC driving mode, while the essential condition is to attain the sinusoidal air gap flux density distribution. A practical technique of rotor shape modification is employed. One of IPM's important advantages over SPM can be clearly illustrated in Figure 7, where it can be seen that it is much simpler to precisely manufacture the rotor lamination's outer shape in IPMs, than the magnet's outer shape in SPMs. This also leads to some other desirable characteristics:

- IPMs use simple rectangular-shape magnets with parallel magnetization -reducing magnet price and manufacturing cost;

- $\quad$ the magnets are mechanically protected -suitable for high speed operation without protective rings or retaining sleeves on the rotor; 
- $\quad$ resence of flux bridge makes the magnets better protected against demagnetization -offering high overloading capability.

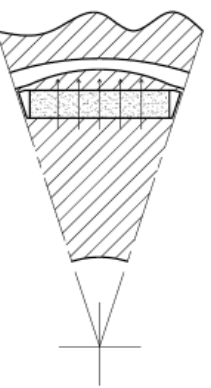

(a) (b)

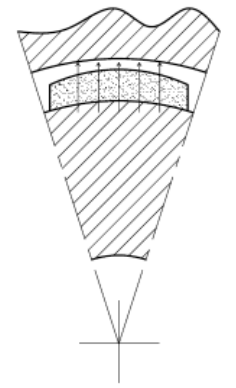

Figure 7: Rotor outer shape modifications for sinusoidal air gap flux density, (a) IPM and (b) SPM.

Besides, it is noteworthy that cogging torque minimization comes along with the gain of sinusoidal air gap flux density distribution.

\section{Performance evaluation}

A commercial FE software MagneForce is used to evaluate the machine performance by two-dimensional (2-D) FEA.

\section{A. Air gap flux density}

As analyzed before, a non-uniform air gap is introduced to obtain sinusoidal flux density distribution, hence sinusoidal back-EMF and negligible cogging torque. The air gap flux density distributions at conditions of no load and full load are given in Figure 8. And the corresponding harmonic components are shown in Figure 9. Since the third harmonic will be eradicated across the line windings, the effective higher harmonic contents are seen relatively small compared with the fundamental, and a good sinusoidal back-EMF is expected.

\section{B. Back-EMF}

The three phase back-EMF at the rated speed of $600 \mathrm{rpm}$ is shown in Figure 10, which are visually seen very symmetrical. Fourier analysis is then undertaken to evaluate the harmonic content of the spectrum. The total harmonic distortion (THD) is found to be $0.67 \%$, which means that the back-EMF is essentially sinusoidal.

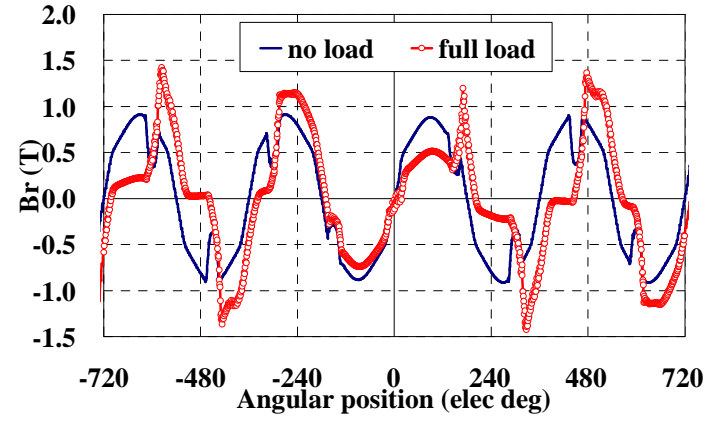

Figure 8: Air gap flux density distribution.

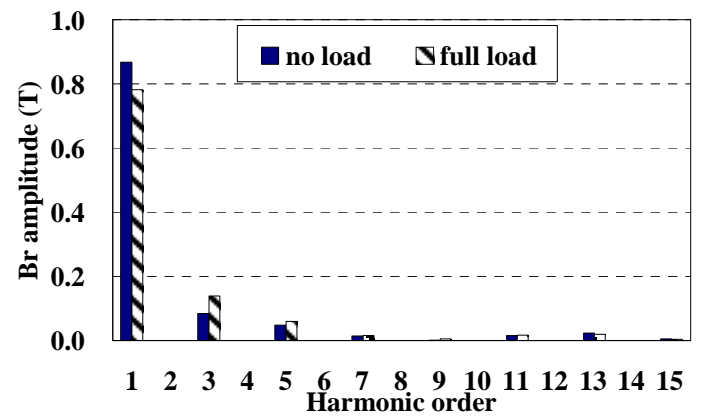

Figure 9: Harmonic components of air gap flux density.

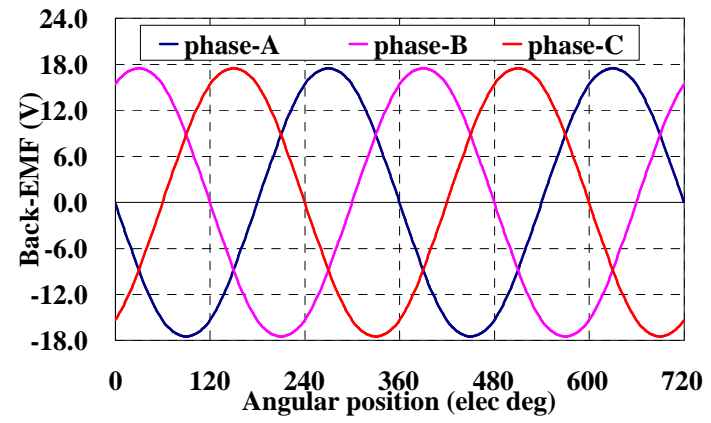

Figure 10: Back-EMF waveforms of the proposed motor at speed of $600 \mathrm{rpm}$.

\section{Inductance}

Taking the saturation effects into account, the load will affect the permeance, which will result in inductance variation. Based on FEA, $L_{d}$ and $L_{q}$ are calculated with different load conditions, i.e. variation of phase current with different amplitudes and advanced commutation angles. The results are shown in Figure 11 and 12 respectively. The ratio $L_{q} / L_{d}$ represents for the saliency level of a PM machine, which is determined by the physical structure and load condition, and is related to the reluctance torque. Figure 13 shows the variation of $L_{q} / L_{d}$. 


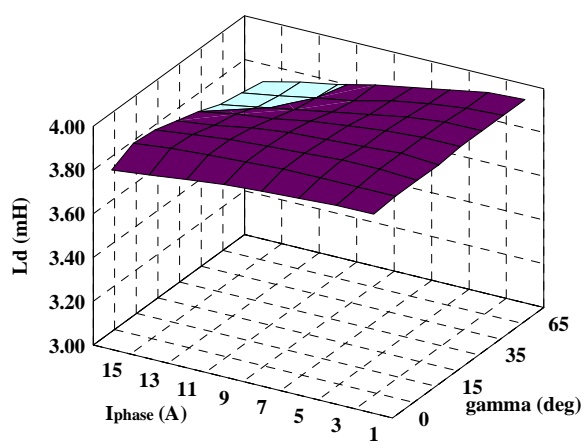

Figure 11: $L_{d}$ as a function of phase current and advanced commutation angle.

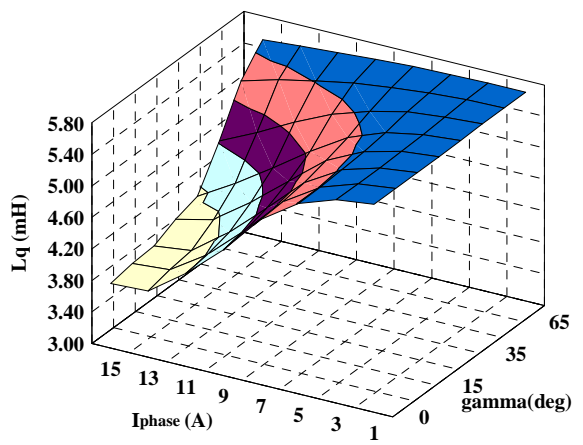

Figure 12: $L_{q}$ as a function of phase current and advanced commutation angle.

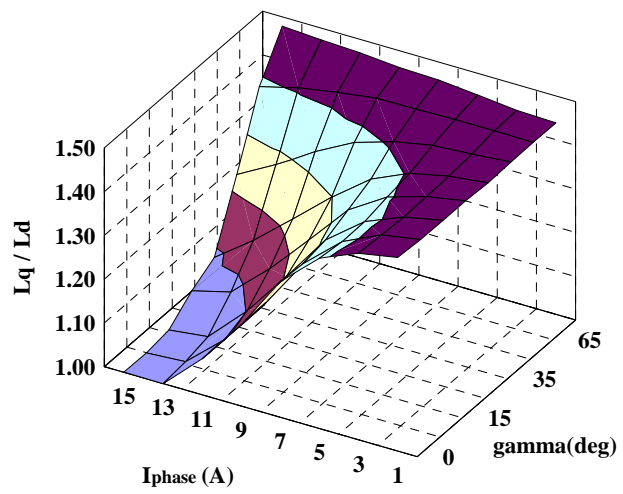

Figure 13: $L_{q} / L_{d}$ as a function of phase current and advanced commutation angle.

During operations at higher load, $L_{q}$ varies in the range of almost $40 \%$, while $L_{d}$ varies in the range of $5 \%$ only. This can be explained by the cross-coupling effects between $d$ - and $q$ - axes, as a result of high magnetic saturation. It is generally known that operations with high magnetic saturation are inherent design features for electric machines with high power density [17].

\section{Torque}

The electromagnetic torque is calculated according to equation (1) under different load conditions, as shown in Figure 14. The maximum torque occurs when the advanced commutation angle is about $25^{\circ}$. And the separated reluctance torque component is also computed according to equation (5) by utilizing the FEA data obtained in calculating the electromagnetic torque, in order to save simulation time, as demonstrated in Figure 15.

$$
T_{r}=\frac{3}{2} p\left(L_{d}-L_{q}\right) i_{d} \cdot i_{q}
$$

Torque ripple should be completely minimized to ensure accurate steering and comfortable driving experience. In general, torque ripple consists of two components, viz., the load dependent component and the load independent component. The former can be extensively ameliorated by employing BLAC mode, and the latter is essentially the cogging torque of the machine, which has already been reduced by means of a sinusoidal air gap flux density distribution, as indicated in Figure 16. Figure 17 shows the output torque waveform at full load condition, where the smoothness of the torque is evident. From the zoomed-in view of the torque ripple in Figure 18, it is further confirmed that the peak to peak torque ripple is $0.17 \mathrm{Nm}$, or $2.2 \%$ of the average output torque, which well exceeds the requirement of less than $3 \%$.

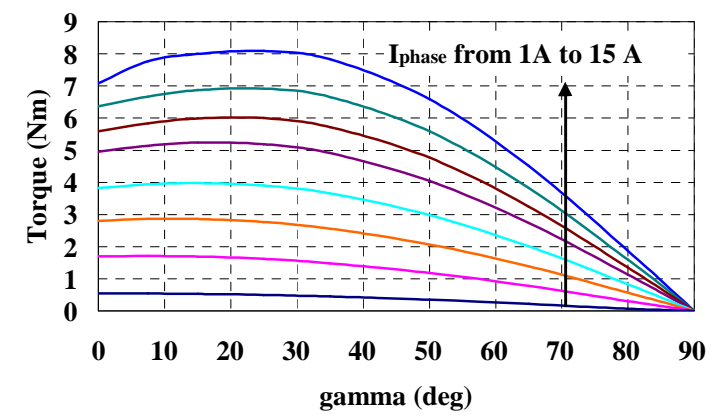

Figure 14: Electromagnetic torque as a function of phase current and advanced commutation angle.

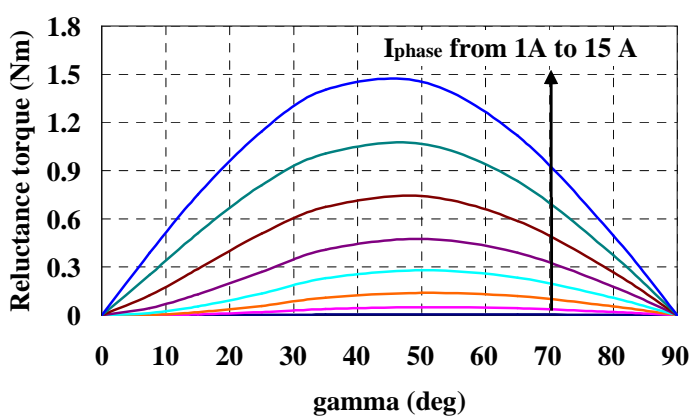

Figure 15: Reluctance torque as a function of phase current and advanced commutation angle. 


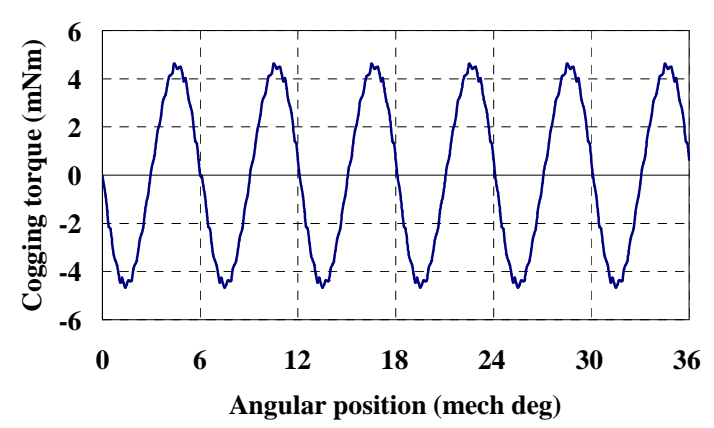

Figure 16: Cogging torque waveform.

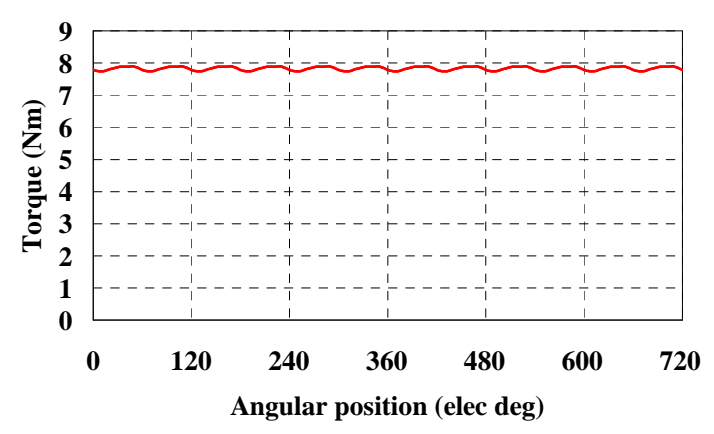

Figure 17: Output torque waveform.

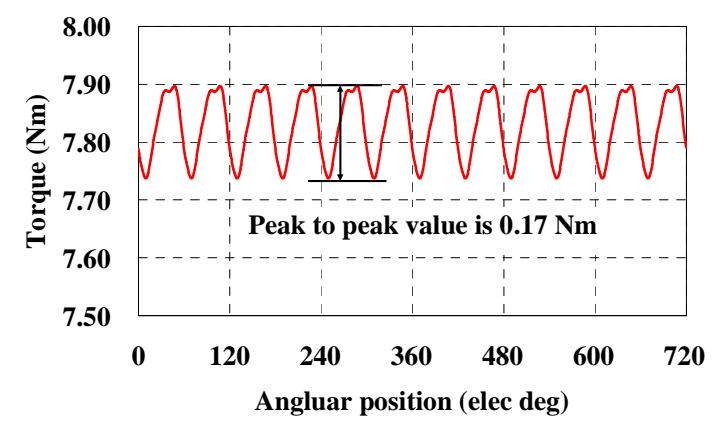

Figure 18: Zoomed-in view of torque ripple.

\section{E. Losses and efficiency}

For EPS applications, the machine runs at low and moderate speed, where electromagnetic losses dominate the total losses. Thus, only the electromagnetic losses are evaluated here. Electromagnetic losses mainly include copper losses in the stator windings $P_{C u}$, iron losses in the stator and rotor laminations $P_{F e}$ and eddy current losses in the magnets $P_{P M}$. The power flow can be expressed by,

$$
P_{\text {in }}=P_{C u}+P_{F e}+P_{P M}+P_{\text {out }}
$$

Apparently, copper losses are the main part considering that the iron losses and eddy current losses are often small or negligible at low speed. Based on these assumptions, the efficiency map of the proposed motor as a function of phase current and advanced commutation angle is computed and is given in Figure 19.

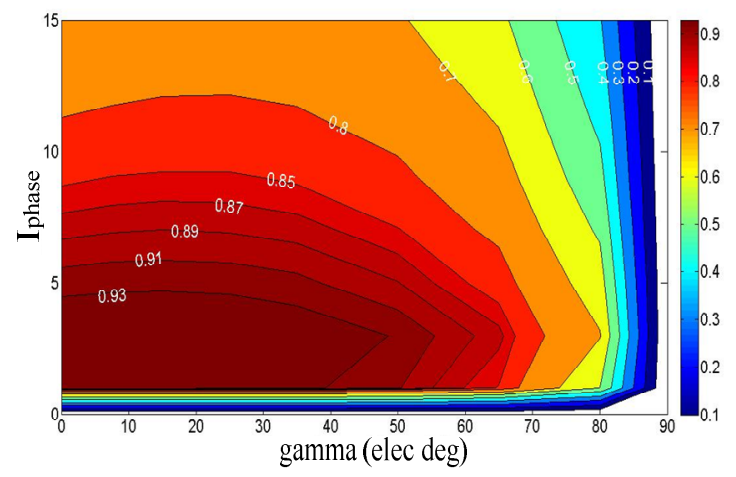

Figure 19: Efficiency map as a function of phase current and advanced commutation angle.

\section{F Frame and prototype}

Considerable efforts have also been spent on the final mechanical design of the machine, which is shown in Figure 20. A prototype, shown in Figure 21, has been built for validation, which will be the subject of future work.

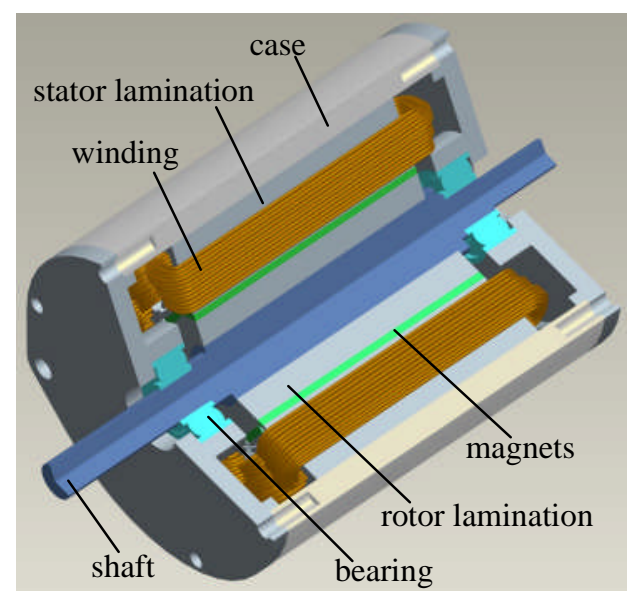

Figure 20: Frame of the proposed motor

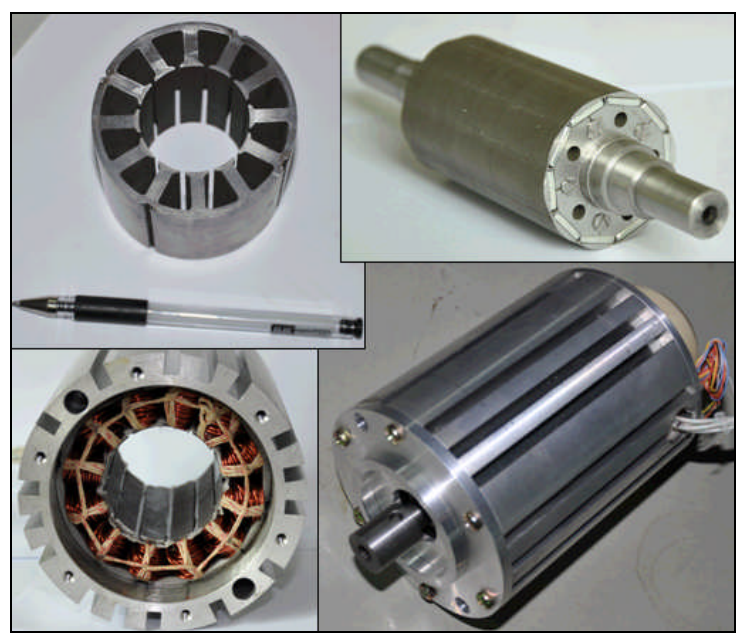

Figure 21: Prototype of the proposed motor

\section{Conclusions}

A full design procedure of an brushless PM motor drive system used for EPS applications 
is proposed. The requirements of the EPS application are firstly introduced and the specifications of the desired machine are then deduced. For correct selection of the right machine topology before detailed electromagnetic machine design, critical issues including operation mode, rotor structure and slot/pole combination are first analyzed. Consequently, the IPM rotor type, BLAC operation mode and $12 \mathrm{~s} / 10 \mathrm{p}$ combination have been selected for further design. The final design is fully optimized by FEA. Subsequently, the characteristics of the proposed machine such as air gap flux density, back-EMF, inductance, output torque, cogging torque, torque ripple, losses and efficiency, are evaluated. The comprehensive 2-D FEA results verify that the design fully meets the requirements of the steering system. Finally, the mechanical design is shown and a prototype motor has been built for verification in future work.

\section{Acknowledgement}

The first two authors gratefully acknowledge the internship supported by the Department of Engineering Systems and Management, Cranfield University, UK, to which this work relates. All authors would like to thank Nanyuan Electric Machinery Co., China for manufacture of the prototype machine, and MagneForce Software Systems Inc., USA for offering evaluation license of MagneForce V4.0.

\section{References}

[1] http://www.globalinsight.com/gcpath/AutoSha nghaiAgendaChinese.pdf

[2] Yoneda, M., Shoji, M., Yongjae Kim and Dohmeki, H.; "Novel Selection of the Slot/Pole Ratio of the PMSM for Auxiliary Automobile," Ind. App. Conf., 2006. 41st IAS Annu. Meeting, Conference Record vol.1, pp.812 Oct. 2006.

[3] Oprea, C., Martis, C.; "Fault tolerant permanent magnet synchronous machine for electric power steering systems", Power Electronics, Electrical Drives, Automation and Motion, 2008. SPEEDAM 2008. International Symposium on 11-13 June 2008 pp.256 - 261.

[4] T. M. Jahns and W. L. Soong; "Pulsating torque minimization techniques for permanent magnet AC motor drives - A review", IEEE Trans. on Ind. Electronics, vol. 43, no. 2, pp. 321-330, April 1996.

[5] N. Bianchi and S. Bolognani; "Design techniques for reducing the cogging torque in surface-mounted PM motors", IEEE Trans. on Industry Applications, vol. 38, no. 5, pp. 12591265, September/October 2002.
[6] M. Islam, S. Mir, and T. Sebastian; "Issues in reducing the cogging torque of mass-produced permanent magnet brushless dc motor," Proc. $38^{\text {th }}$ IEEE Ind. App. Annu. Meeting, Salt Lake City, Oct. 12-16, 2003, pp. 393-400.

[7] M. Islam, S. Mir, S.; Sebastian, T. Underwood, S.; "Design considerations of sinusoidally excited permanent magnet machines for low torque ripple applications", Ind. App. Conf., 2004. 39th IAS Annu. Meeting. vol. 3, 3-7 Oct. 2004 pp.1723 - 1730.

[8] G. Ombach, J. Junak, and A. Ackva; "Vibrations optimization of brushless power steering motor with taking into account magnetostriction effects," 17th International Conference on Electrical Machines, Greece 25 September 2006

[9] Seong Taek Lee, Burress, T.A., and Tolbert, L.M; "Power-factor and torque calculation with consideration of cross saturation of the interior permanent magnet synchronous motor with brushless field excitation", Electric Machines and Drives Conference, 2009. IEMDC '09. IEEE International 3-6 May 2009 pp.317 - 322.

[10] B. Stumberger, G. Stumberger, D. Dolinar, A. Hamler, and M. Trlep; "Evaluation of Saturation and Cross-Magnetization Effects in Interior Permanent-Magnet Synchronous Motor," IEEE Trans. on Ind. App., vol. 39, no. 5, 2003, pp.1264-1271.

[11]L. Chedot and G. Friedrich, "A Cross Saturation Model for Interior Permanent Magnet Synchronous Machine. Application to a Starter-Generator," IEEE Ind. App. Society Annu. Meeting, Oct.3-7, 2004, Seattle, Washington, pp. 64-70.

[12] Yamazaki, K, and Ishigami, H.; "Rotor Shape Optimization of Interior Permanent Magnet Motors to Reduce Harmonic Iron Losses" Ind. Electronics IEEE Trans. on, Accepted for future publication 2009.

[13] V. Zivotic-Kukolji, W. L. Soong, and N. Ertugrul, "Iron loss reduction in an interior PM automotive alternator", IEEE Trans. Ind. App., vol. 42, no.6, pp.1478-1486, 2006.

[14] Bianchi, N.; Pre, M.D.; Bolognani, S.; "Design of a fault-tolerant IPM motor for electric power steering", Vehicular Technology, IEEE Trans. on vol.55, no.4, July 2006 pp.1102 1111

[15] G. Aroquiadassou, H. Henao, V. Lanfranchi, F. Betin, B. Nahidmobarakeh, G. Capolino, M. Biedinger, G. Friedrich, "Design comparison of two rotating electrical machines for $42 \mathrm{~V}$ electric power steering"; Electric Machines and Drives, 2005 IEEE International Conference on 15-15 May 2005 pp.431 - 436

[16] G. Ombach, J. Junak, "Two rotors designs' comparison of permanent magnet brushless synchronous motor for an electric power steering application" Power Electronics and Applications, 2007 European Conference on 25 Sept. 2007, pp. 1 - 9 
[17] G. Ombach, J. Junak, "Comparison of doublelayer interior permanent magnet synchronous motor design with two different pole numbers", Electrical Machines, 2008. ICEM 2008. 18th International Conference on 6-9 Sept. 2008, pp. 1 - 6

[18]Z. Q. Zhu, "Fractional Slot PM Brushless Machines and Drives for Electric and Hybrid Propulsion Systems" The International Conference and Exhibition on Ecological Vehicles and Renewable Energies EVER'09 plenary speech, March 2009.

[19] Y. Shi, Z. Zhu, D. Howe, "Torque-Speed Characteristics of Interior-Magnet Machines in Brushless AC and DC Modes, with Particular Reference to Their Flux-Weakening Performance", Power Electronics and Motion Control Conference, 2006. IPEMC 2006. CES/IEEE 5th International vol. 3, 14-16 Aug. 2006 pp.1-5.

[20]P. J. Otaduy, J. W. McKeever, "Modeling reluctance-assisted PM motors," Oak Ridge National Laboratory, January 2006. 